IZA DP No. 7413

Worker Identity, Employment Fluctuations and Stabilization Policy

Dennis J. Snower

Wolfgang Lechthaler

May 2013 


\title{
Worker Identity, Employment Fluctuations and Stabilization Policy
}

\author{
Dennis J. Snower \\ Kiel Institute for the World Economy, \\ Christian-Albrechts-University of Kiel, CEPR and IZA \\ Wolfgang Lechthaler \\ Kiel Institute for the World Economy
}

Discussion Paper No. 7413

May 2013

IZA

P.O. Box 7240

53072 Bonn

Germany

Phone: +49-228-3894-0

Fax: +49-228-3894-180

E-mail: iza@iza.org

\begin{abstract}
Any opinions expressed here are those of the author(s) and not those of IZA. Research published in this series may include views on policy, but the institute itself takes no institutional policy positions. The IZA research network is committed to the IZA Guiding Principles of Research Integrity.

The Institute for the Study of Labor (IZA) in Bonn is a local and virtual international research center and a place of communication between science, politics and business. IZA is an independent nonprofit organization supported by Deutsche Post Foundation. The center is associated with the University of Bonn and offers a stimulating research environment through its international network, workshops and conferences, data service, project support, research visits and doctoral program. IZA engages in (i) original and internationally competitive research in all fields of labor economics, (ii) development of policy concepts, and (iii) dissemination of research results and concepts to the interested public.
\end{abstract}

IZA Discussion Papers often represent preliminary work and are circulated to encourage discussion. Citation of such a paper should account for its provisional character. A revised version may be available directly from the author. 
IZA Discussion Paper No. 7413

May 2013

\section{ABSTRACT}

\section{Worker Identity, Employment Fluctuations and Stabilization Policy}

This paper provides a model of "social hysteresis" whereby long, deep recessions demotivate workers and thereby lead them to change their work ethic. In switching from a pro-work to an anti-work identity, their incentives to seek and retain work fall and consequently their employment chances fall. In this way, temporary recessions may come to have permanent effects on aggregate employment. We also show that these permanent effects, along with the underlying identity switches, can be avoided through stabilization policy. The size of the government expenditure multiplier can be shown to depend on the composition of identities in the workforce.

JEL Classification: E24, E60, J21, J28

Keywords: economics of identity, work ethic, hysteresis, business cycle policy

Corresponding author:

Dennis J. Snower

Kiel Institute for the World Economy

Duesternbrooker Weg 120

24105 Kiel

Germany

E-mail: dennis.snower@ifw-kiel.de 


\section{Introduction}

The idea underlying this paper is a simple one - well-known to policy makers, but largely overlooked in economic analysis. When long, deep recessions seriously impair people's employment prospects, highly motivated workers may become demotivated because they change their attitude to work. In good times, when workers have good chances to find jobs at good wages, they often adopt a positive work ethic, feeling comfortable when at work and uncomfortable out of it. In other words, they choose a pro-work identity, associated with a relatively low disutility of work. This identity induces them to seek and retain work, and thereby contributes to the economy's high employment rate. When a long, deep recession strikes, however, this pro-work identity tends to make workers unhappy, since being unemployed is particularly disagreeable under this identity. Consequently, workers may decide to adopt an anti-work identity, identifying with people who are unemployed. This identity switch not only deepens the recession but can also lead to permanent effects on employment and output. After a long and severe recession economic activity might remain at a permanently lower level, because some workers adapt to a new anti-work life style.

These considerations have important implications for macroeconomic policy. If the government responds slowly to a recession, allowing adverse identity changes to occur, it may prove much more costly to bring the economy back to its initial level of production than if the government response had come before the identity changed. For then large numbers of workers will have adopted an anti-work identity and thus expansionary macroeconomic policy is relatively ineffective. On this account, it is desirable for the government to react swiftly to major recessions, counteracting the economic downturn promptly through expansionary fiscal policy, and thereby preventing an adverse identity change from taking place. This is a potentially powerful, novel rationale for macroeconomic stabilization policy.

This paper derives these results from a simple model of identity formation, building on the pathbreaking work of Akerlof and Kranton (2000, 2005), in which 
people's preferences depend on their identities, linked to compliance with ideal behavior in social groups. As indicated in section 2, there is a large empirical literature confirming that social aspects play a crucial role in labor markets. Thus far, however, these aspects have received little attention in the theoretical labor market literature.

In our model, workers can adopt either an "elite" or "underclass" identity. An elite worker has a pro-work ethic, with a low disutility of work and a high disutility from being unemployed. This gives the worker a strong incentive to take up work and thereby raises her job finding rate. Conversely, the underclass worker has an anti-work ethic, with a high disutility of work and a low disutility from being unemployed, leading to a lower job finding rate. We assume that workers choose their identities in order to maximize the present value of their welfare. The paper shows how a severe, prolonged recession can lead to elite workers to choose an underclass identity. It also shows how stabilization policy can prevent this identity switch from taking place.

In this way our model provides a rationale for "social hysteresis," whereby temporary shocks can have permanent effects on labor market activity because of workers' identity choices. This may help explain the upward ratchet of unemployment rates in many European countries from the 1970s to the mid-1990s, as illustrated in Figure 1 for Germany. Although this phenomenon has traditionally not been associated with the U.S. economy, even here evidence for long-lasting effects of recessions can be found. Figure 2 shows the employmentpopulation ratio in the US before, during and after the Great Recession of $2008 / 2009$. It can be seen that the exceptionally deep recession lead to a huge drop in the employment-population ratio which so far has not recovered at all. Some prominent commentators worry that this drop may persist. This kind of behavior is difficult to explain in terms of standard labor market models. This paper provides a rationale for this phenomenon in terms of identity-switching in response to large macroeconomic shocks.

Our rationale for unemployment hysteresis is quite distinct from other rationales for unemployment hysteresis and persistence, such as those based on habits 


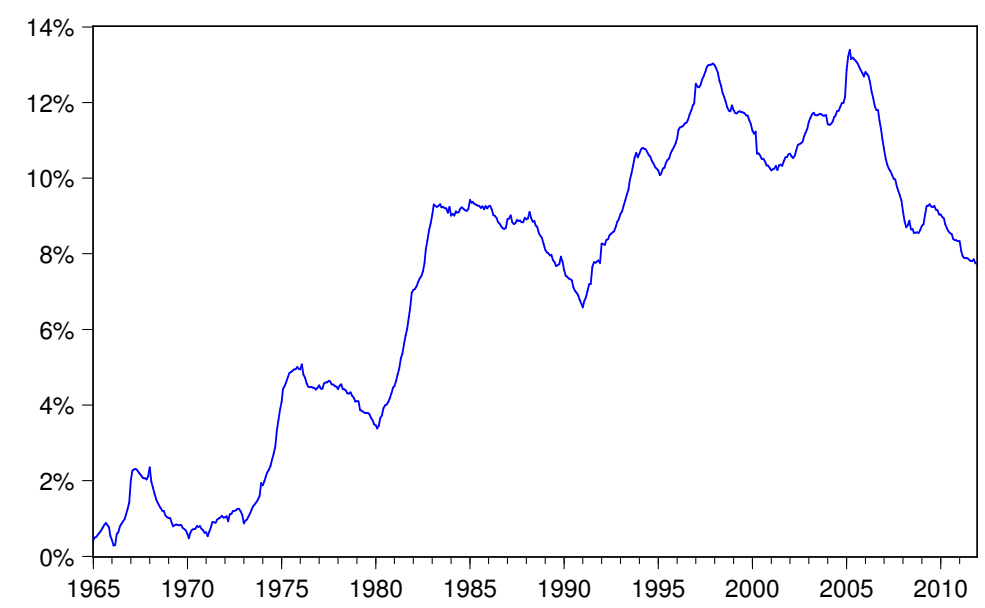

Figure 1: German unemployment rate

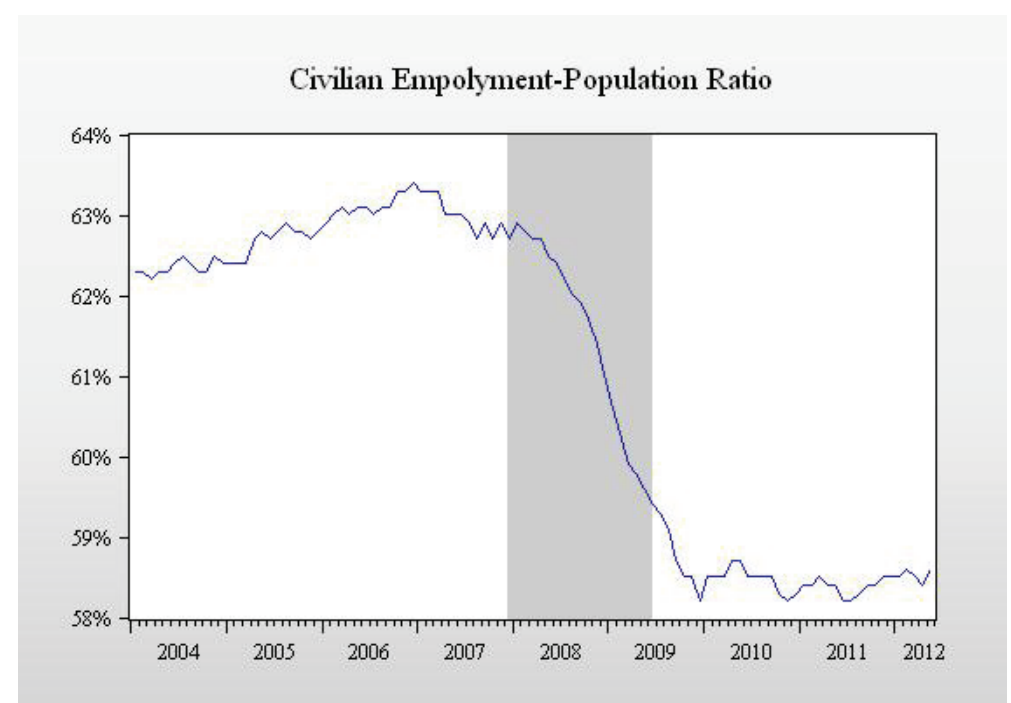

Figure 2: Employment-population ratio in the US 
(e.g. Vendrik (1993)), labor turnover costs (e.g. Lindbeck and Snower (1986)), union membership (e.g. Blanchard and Summers (1986), Lindbeck and Snower (1987)) or human capital (e.g. Ljungqvist and Sargent (1998)). In the rationale resting on habit formation, an increase in the unemployment rate is associated with an increase in workers' leisure, which raises the marginal utility of leisure in the future. In our analysis, by contrast, an increase in the unemployment rate may lead elite workers to adopt an underclass identity. This identity is associated with a change in habits (not a continuation of past habits). After all, elite workers have high job acceptance rates because they like to work, whereas underclass workers have low job acceptance rates because they consider work onerous. What induces elite workers, under conditions of high unemployment, to switch identity is that they wish to avoid the cost of betraying their identity through remaining idle.

In the rationale resting on labor turnover costs, an increase in unemployment persists because hiring costs and the prospect of future firing costs discourage firms from hiring the newly unemployed workers (and similarly with regard to other labor turnover costs). In the union-membership rationale, an increase in unemployment leads to a reduction in union membership (since union members tend to be employed) and the reduced union members set their wages without sufficient regard for the employment opportunities of the unemployed. By contrast, the identity-switching decisions in our analysis do not depend on the existence of labor turnover costs or unions, nor are identity-switching costs necessarily associated with labor turnover costs or union membership. Finally, a switch in identity is not necessarily associated with a loss in human capital. Workers may lose their pro-work identity even when their human capital is still intact.

The labor market experiences of many European countries call for a different notion of "elite" and "underclass" workers than those of the U.S. In Europe the distinction is aptly drawn along the lines above - namely, between working-age workers for whom employment is a way of life versus those for whom unemployment and inactivity is the preferred norm. By contrast, in the U.S. (where 
genuine long-term unemployment is uncommon due to the absence of substantial long-term unemployment benefits) the appropriate distinction is between workers in legal employment and those in the shadow economy (including criminal activities). Under both interpretations, the elite workers are attached to activities that appear in the official employment statistics, whereas the underclass workers are not. Furthermore, in both cases the elite workers tend to be more productive than the underclass workers. ${ }^{1}$

Our paper is related to two distinct literatures, (i) the modeling of social interactions in labor markets and (ii) the modeling of labor force participation in search and matching models. Lindbeck, Nyberg, and Joergen $(1999,2003)$ show that the takeup of unemployment benefits is associated with a social cost which depends on the number of workers being unemployed. If the number of unemployed workers is high then the social pressure on the unemployed decreases because it becomes more "normal" to be unemployed. Here habituation to unemployment arises from the social milieu, whereas in in our model the habituation occurs at the personal level: Workers who see their future employment prospects decline get accustomed to being unemployed. Beyond that, the focus of our paper is different, since we focus on the long-term effects of recessions and stabilization policy. ${ }^{2}$ Farmer (2012) brings together search and matching unemployment and animal spirits. In his model self-fulfilling beliefs of stock-market participants select one equilibrium among a continuum of possible equilibria. He does not model social norms and attitudes towards work, which lie at the heart of this paper. ${ }^{3}$

\footnotetext{
${ }^{1}$ Unemployed workers make no contribution to aggregate output, whereas illegal activities reduce average productivity, say, through the effects of drugs or the costs of crime prevention.

${ }^{2}$ Furthermore, the models of Lindbeck et al give rise to multiple equilibria but only through political economy dynamics, whereas in our model there is a continuum of potential equilibria at any time, even in the absence of political economy dynamics.

${ }^{3}$ Early contributions on the role of social interactions in labor markets include Akerlof (1980) and Besley and Coate (1992). Darity and Goldsmith (1993, 1996) provide a verbal argument for social hysteresis but do not provide a formal model. Other papers highlighting the role of social identities both from the theoretical and empirical perspective include Benabou and Tirole (2006), Koeszegi (2006), Klor and Shayo (2010), Battu, Mwale, and Zenou (2007),
} 
To endogenize labor force participation in search and matching models it is typically assumed that workers have either participation costs (see, e.g., Pries and Rogerson (2009)) or utility from home production (see, e.g., Garibaldi and Wasmer (2005)) and Pissarides (2000)). Berkovitch (1990), Bjornstad (2006) and Sunde, Huffmann, and Falk (2011) adduce signalling effects and learning to explain why job finding rates tend to fall as the unemployment spell lengthens. We offer a new explanation based on the idea that discouraged workers may adapt to their new lifestyle by adopting an identity associated with an antiwork ethic.

There is a growing empirical literature consonant with the idea that workers' choice of identity is important for the chances of finding employment. There is evidence that (i) workers commonly find it unpleasant to remain unemployed, (ii) the degree of unpleasantness is associated with their social relations to other members of the population and (iii) the degree of unpleasantness is associated with the expected duration of employment and unemployment, which in turn affect their social relations. In the following we will describe each aspect in more detail.

The paper is organized as follows. Section 2 discusses the related empirical literature. Section 3 presents our model and describes its steady-state behavior. Section 4 analyzes the responsiveness of the economy to adverse macroeconomic shocks and the effectiveness of macroeconomic policy under different identity scenarios. Finally, Section 5 concludes.

Darity, Mason, and Stewart (2006), Austen-Smith and Fryer (2005), Mason (2004), Pendakur and Pendakur (2005) and Bisin, Patacchini, Verdier, and Zenou (2011). 


\section{Empirical literature on social aspects in labor markets}

There is a large and growing empirical literature indicating that people dislike unemployment, even controlling for differences in income. ${ }^{4}$ For example, Clark and Oswald (1994), using the General Health Questionnaire (GHQ) of the British Household Panel Survey, find that the mental well-being of unemployed workers is significantly lower than that of employed workers. They report that "... joblessness depresses well-being more than any other single characteristic (including important negative ones such as divorce and separation)" (page 655). Winkelmann and Winkelmann (1998) use the German Socio-Economic Panel (GSOEP), which offers the advantage of repeated observations for the same individual. This allows to control for unobserved individual effects and thus allows to infer the direction of causality. They argue that unemployment indeed causes dissatisfaction and that the effect is considerably larger than the pecuniary costs of unemployment. Kassenboehmer and Haisken-DeNew (2009) use information on plant closures to infer causality and confirm that unemployment causes dissatisfaction. While these results appear hardly surprising, they are nevertheless almost completely ignored in the labor literature, which instead focuses almost exclusively on the pecuniary effects. Our analysis takes these results seriously by adopting a model in which workers suffer disutility from being unemployed.

Clark (2003), using the GHQ, and Clark, Georgellis, and Sanfey (2001), using the GSOEP, do not only find that unemployed workers have lower well-being, but also that those individuals who suffer the sharpest decline in well-being have the highest probability of getting back to work in the future. Stutzer and Lalive (2004) use a nationwide referendum on unemployment benefits in Switzerland to test social norms. They find that those communities who voted for lower unemployment benefits have lower unemployment durations and that in these regions

\footnotetext{
${ }^{4}$ For a review of the economic literature on subjective wellbeing see Dolan, Peasgood, and White (2008)
} 
unemployment is associated with higher decreases in subjective well-being. By allowing for disutility from being unemployed, our model is consonant with such phenomena. Workers with a pro-work identity, who dislike unemployment more strongly than underclass workers, have relatively low unemployment durations, ceteris paribus, and thus relatively little dependence on unemployment benefits.

Clark (2003) also stresses the important role of reference groups (at the regional, household or partner level). It is found that unemployed workers whose reference groups have higher unemployment rates suffer lower decreases in subjective well-being. These results are in line with an other strand of the literature which finds positive correlations between individual unemployment rates and neighborhood unemployment rates (see, e.g., Bauer, Fertig, and Vorell (2011), Hoynes (2000) or van der Klaauw and van Ours (2003)).

The evidence on the effect of unemployment duration on subjective wellbeing is mixed. While Winkelmann and Winkelmann (1998) do not find an effect, both Warr and Jackson (1987) and Goldsmith, Veum, and Darity (1996) find that the decrease in subjective well-being is smaller for workers who have been unemployed for longer. Furthermore, Warr and Jackson argue that this effect can be partly explained by the significant decrease in a person's commitment to the labor market. Clark, Diener, Georgellis, and Lucas (2008) find that after five years of unemployment the subjective well-being of men is still significantly lower than before the unemployment spell. However, the estimated coefficient for five years and more of unemployment is only two-thirds of the coefficient for one and two years. For women there are no significant long-run effects. Clark, Georgellis, and Sanfey (2001) find that the decrease in subjective well-being suffered from present unemployment is lower for workers who had more unemployment spells in the past. Finally, Winkelmann and Winkelmann (1998) find that the decrease in subjective wellbeing is lower for workers out of the labor force than for unemployed workers.

To summarize, the empirical literature indicates that, while most workers suffer a substantial fall in their subjective well-being when they become unemployed, this fall is smaller for workers who have been unemployed many times, 
for workers whose reference group faces a relatively high unemployment rate and for workers out of the labor force. Thus there is a large degree of heterogeneity regarding the costs of unemployment. Some workers suffer strongly when they become unemployed, while others seem to be affected by less. Our model allows for such heterogeneity, by allowing workers to adopt alternative identities, differing with respect to work ethic and allowing workers to switch identities.

\section{The Model}

\subsection{The Employment Decision}

In this section we first describe the employment decision of workers for a given worker identity and discuss how worker identity affects the employment decision. Then we show how workers choose their identity.

Workers can be classified by their activity (employed or unemployed) and by their identity. Workers have either an "elite" or an "underclass" identity. Those with an elite identity have a pro-work ethic, involving a relatively low disutility from work and a relatively high disutility from being unemployed; those with an underclass identity have an anti-work ethic, associated with the opposite relative disutilities. For simplicity, we will assume that an elite worker's disutility from unemployment is $c$ (a positive constant) and her disutility from work is zero, whereas an underclass worker's disutility from work is $c$ and her disutility from unemployment is zero. ${ }^{5}$

Furthermore, workers can change their identity, provided that they pay an identity-switching cost of $s$ (also a positive constant). This cost is the psychic cost of identifying with a new social group and could be interpreted as the cost of adopting to a new life-style, of reorganizing one's daily routine or of finding new peer groups. It is meant to capture the fact that people don't switch their identity lightly. For simplicity, we assume that both the cost of switching from

\footnotetext{
${ }^{5}$ More generally, we could let $c_{w}^{U}$ and $c_{w}^{E}$ denote the disutility from work of underclass workers and elite workers, respectively, and $c_{u}^{U}$ and $c_{u}^{E}$ denote their disutility from being unemployed. All that matters for the results in our model is that $c_{w}^{U}>c_{w}^{E}$ and $c_{u}^{U}<c_{u}^{E}$.
} 
a pro-work to an anti-work identity and the cost of switching in the opposite direction are both equal to $s$.

Workers make their employment and identity decisions with a view to maximizing their utility. To generate transparent results, we specify the utility and the production function in very simple form. Utility is linear in income and there are constant returns to labor: the worker's productivity is $a_{t} \alpha_{i} \varepsilon_{i, t}$, where (i) $a_{t}$ is "aggregate productivity," i.e. a common factor in all worker's productivity, (ii) $\alpha_{i}$ is a time-invariant, worker-specific component of productivity, which may be interpreted as the worker $i$ 's ability and (iii) $\varepsilon_{i, t}$ is a stochastic productivity component, which is iid across workers and time. The worker-specific component $\alpha_{i}$ is distributed with density function $g\left(\alpha_{i}\right)$. The stochastic component $\varepsilon_{i, t}$ has a stable density function $f\left(\varepsilon_{i, t}\right)$.

For the moment we assume that $a_{t}=a$ is constant. Later we will consider the case of a recession that is characterized by a temporary decrease in $a$. To make the role of identity choice in our model particularly transparent and to derive transparent analytical results, we make the simplifying assumption that the labor market is a competitive spot market, i.e., the worker earns her marginal product and there are no labor turnover costs (such as costs of hiring and firing). This implies that the probability of working in the current period is independent of the employment status in the previous period. ${ }^{6}$

An employed worker earns her marginal product, so that the wage is $w_{t}=$ $a_{t} \alpha_{i} \varepsilon_{i, t}$. An unemployed worker receives $b$, a positive constant interpreted as unemployment benefits (financed by a lump sum tax). As common in the literature, we assume that unemployment benefits are exogenously given and constant.

\footnotetext{
${ }^{6}$ This simplifying assumption understates the role of identity choice in employment determination. In practice, labor turnover costs imply that the retention rates of currently employed workers are usually significantly greater than hiring rates of new entrants. Thus, when a long, deep recession occurs, the dismissed workers anticipate that their employment probability will fall and this strengthens their incentive to adopt an anti-work identity. Analogously, when there is a long, pronounced boom, the newly hired workers have a strengthened incentive to adopt a pro-work identity.
} 
Since identities tend to be very persistent through time and are changed infrequently, we focus our analysis on circumstances in which the identity switching costs are so high that it does not pay to switch identity unless the economy is hit by a "severe shock," to be specified below.

Let $\eta_{i, t}^{E}$ be the elite worker $i$ 's probability of being employed at time $t$ :

$$
\eta_{i, t}^{E}=\int_{v_{i, t}^{E}}^{\infty} f\left(\varepsilon_{i, t}\right) d \varepsilon_{i, t},
$$

where $v_{i, t}^{E}$ is the threshold value of the elite worker's idiosyncratic component of productivity, above which the worker accepts a job. The variable $v_{i, t}^{E}$ will be further specified below. The underclass worker's probability of being employed is

$$
\eta_{i, t}^{U}=\int_{v_{i, t}^{U}}^{\infty} f\left(\varepsilon_{i, t}\right) d \varepsilon_{i, t},
$$

where $v_{i, t}^{U}$ is the underclass worker's threshold value of the idiosyncratic productivity component, above which the worker accepts a job.

Let $\beta=1 / 1+r$ be the worker's discount factor, where $r$ is the discount rate. Then, in the absence of a severe shock and a constant aggregate productivity $a$, an employed elite worker's present value of utility is

$$
W_{i, t}^{E}=a \alpha_{i} \varepsilon_{i, t}+\beta V_{i . t+1}^{E}
$$

where

$$
V_{i, t+1}^{E}=\sum_{k=t+1}^{\infty}\left[\beta^{k-t}\left(1-\eta_{i, k}^{E}\right)(b-c)+\beta^{k-t} \int_{v_{i, k}^{E}}^{\infty} a \alpha_{i} \varepsilon_{i, k} f\left(\varepsilon_{i, k}\right) d \varepsilon_{i, k}\right],
$$

is the expected future value of being an elite worker. An unemployed elite worker's present value of utility is

$$
U_{i, t}^{E}=b-c+\beta V_{i, t+1}^{E},
$$

where the disutility from unemployment $c$ is subtracted.

We are now able to derive the elite worker's threshold value of output. The worker $i$ accepts a job when $W_{i, t}^{E}>U_{i, t}^{E}$, which implies that

$$
a \alpha_{i} \varepsilon_{i t}>b-c .
$$


An elite worker will take up work whenever her idiosyncratic productivity is high enough to earn her a wage above $b-c$. Thus, the threshold value of the elite worker's output is

$$
v_{i, t}^{E}=\frac{b-c}{\alpha_{i} a} .
$$

Note that the disutility from unemployment decreases $v_{i, t}^{E}$ and thus increases the employment rate. Along analogous lines, the present value of utility of an employed underclass worker is

$$
W_{i, t}^{U}=a \alpha_{i} \varepsilon_{i t}-c+\beta V_{i, t+1}^{U}
$$

where the disutility from work $c$ is subtracted and

$$
V_{i, t+1}^{U}=\sum_{k=t+1}^{\infty}\left[\beta^{k-t}\left(1-\eta_{i, k}^{U}\right) b+\beta^{k-t} \int_{v_{i, k}^{U}}^{\infty}\left(a \alpha_{i} \varepsilon_{i, k}-c\right) f\left(\varepsilon_{i, k}\right) d \varepsilon_{i, k}\right],
$$

is the expected future value of being an underclass worker. ${ }^{7}$ As stated above, the disutility from unemployment of an underclass worker is assumed to be zero. Finally, the unemployed underclass worker's present value of utility is

$$
U_{i, t}^{U}=b+\beta V_{i, t+1}^{U}
$$

Since the underclass worker accepts at job when $W_{i, t}^{U}>U_{i, t}^{U}$, the threshold value of the worker's output is

$$
v_{i, t}^{U}=\frac{b+c}{\alpha_{i} a} .
$$

By comparison of equations (6) and (10)), it can immediately be seen that elite workers have a higher employment probability since they value work. This is in line with the empirical evidence noted in the introduction.

$$
\begin{aligned}
& { }^{7} \text { More generally the value functions could be written as } \\
& V_{i, t+1}^{E}=\sum_{k=t+1}^{\infty}\left[\beta^{k-t}\left(1-\eta_{i, k}^{E}\right)\left(b-c_{u}^{E}\right)+\beta^{k-t} \int_{v_{i, k}^{E}}^{\infty}\left(a \alpha_{i} \varepsilon_{i, k}-c_{w}^{E}\right) f\left(\varepsilon_{i, k}\right) d \varepsilon_{i, k}\right], \\
& V_{i, t+1}^{U}=\sum_{k=t+1}^{\infty}\left[\beta^{k-t}\left(1-\eta_{i, k}^{U}\right)\left(b-c_{u}^{U}\right)+\beta^{k-t} \int_{v_{i, k}^{U}}^{\infty}\left(a \alpha_{i} \varepsilon_{i, k}-c_{w}^{U}\right) f\left(\varepsilon_{i, k}\right) d \varepsilon_{i, k}\right] .
\end{aligned}
$$

Under the assumption that $c_{w}^{E}=c_{u}^{U}=0$ and $c_{u}^{E}=c_{w}^{U}=c$ these equations collapse to the ones given in the main text. 
The value functions (4) and (8) play a crucial role in our model since they govern the identity decision of workers. Figure 3 plots these value functions in relation to a worker's ability. It can be shown analytically that the value function of elite workers is steeper than the value function of underclass workers and that they intersect each other exactly once:

\section{Proposition 1 Value functions and ability}

- The value of being an underclass worker and the value of being an elite worker both rise with worker ability, i.e., $\partial V^{E} / \partial \alpha>0$ and $\partial V^{U} / \partial \alpha>0$.

- The value of being an elite worker is more responsive to ability than the value of being an underclass worker, i.e., $\partial V^{E} / \partial \alpha>\partial V^{U} / \partial \alpha$.

- Low-ability workers are better off being underclass, while high-ability workers are better off being elite, i.e., $\exists$ as.t. $V^{U}>V^{E}$ and $\exists \alpha$ s.t. $V^{U}<V^{E}$.

(Proof in the appendix.)

Naturally, the ability of a worker only plays a role if she has a job. If she doesn't have a job, she receives unemployment benefits which do not depend on ability. Since elite workers have a higher probability of working, their income depends more strongly on ability. Thus, their value function has to be steeper than the value function of underclass workers.

\subsection{The Identity Decision}

In this section we discuss the conditions under which a worker is satisfied with her current identity. In principle, a worker can switch identity at any time whenever he is willing to pay the switching cost $s$, which is assumed to be higher than the betrayal cost $c: s>c$ (otherwise people would always switch identity in accordance with their employment status, adopting an elite identity when employed and an underclass identity when unemployed). Of course, an elite worker who has a job clearly does not wish to switch identity, because then the worker would have to suffer both the switching cost and the betrayal 


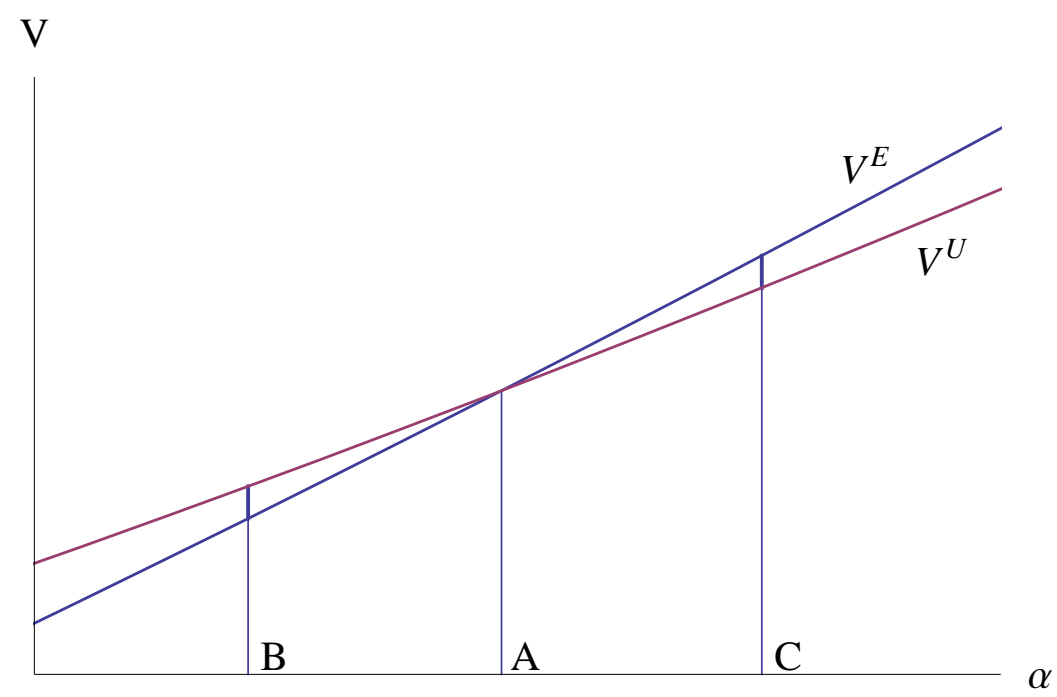

Figure 3: Value functions in dependence of ability

cost. Similarly, an underclass worker who is unemployed does not wish to switch identity. However, unemployed elite workers and employed underclass workers have an incentive to switch identity, when economic conditions force them to betray their identities frequently enough.

The condition for an underclass worker to become elite is

$$
\beta\left(V_{i, t+1}^{E}-V_{i, t+1}^{U}\right)+c>s
$$

i.e. the gain from switching identity (the change in future values plus the saved betrayal cost) has to be higher than the cost of switching status. Similarly, the condition for elite workers to become underclass is

$$
\beta\left(V_{i, t+1}^{U}-V_{i, t+1}^{E}\right)+c>s
$$

Note, that in absence of any changes in the exogenous variables, a worker will switch identity at most once. ${ }^{8}$ According to (11), a necessary condition for

${ }^{8}$ For this reason the economy is fully determined by the equations above even when the economy is not in its steady state. Those workers who consider switching their identity in the 
an underclass worker to switch status is $V_{i, j, t+1}^{E}>V_{i, j, t+1}^{U}$. If this condition is fulfilled, (12) cannot be fulfilled. Naturally the identity decision depends on the ability of the worker. The higher a worker's ability, the higher the probability to have a job and thus the more profitable it is to be elite.

The following proposition summarizes the relationship between ability and identity.

\section{Proposition 2 Identity choice and ability}

If switching costs are not prohibitively high, i.e., if $s<c /(1-\beta)$, then

- Workers of low ability will be underclass workers, i.e., $\exists$ as.t. $V^{U}-V^{E}>$ $s-c$.

- Workers of high ability will be elite workers, i.e., $\exists$ as.t. $V^{E}-V^{U}>s-c$.

- Workers of intermediate ability will keep their inherited identity, i.e., $\exists$ as.t. $V^{U}-V^{E}<s-c$ and $V^{E}-V^{U}<s-c$.

(Proof in the appendix.)

The proposition can be best understood with help of Figure 3. The vertical lines $B$ and $C$ split the domain into three areas, at $B$ the ability is such that $V^{U}-V^{E}=s-c$, at $C$ the ability is such that $V^{E}-V^{U}=s-c$. Thus, based on the vertical distance between the two value functions, three classes of workers can be identified, who make distinctive identity choices:

1. Low-ability workers, below $B$, will eventually become underclass. If they are initially elite, they will switch their identity to underclass as soon as they are hit by an unfavorable idiosyncratic shock. Their employment probability is so low that they are better off being underclass.

2. For intermediate-ability workers, between $B$ and $C$, the gains from switching identity are too low to justify paying $s$. They will keep whatever status they have inherited from the past

current period do not expect to do so again in the future. 
3. High-ability workers, above $C$, will become elite in the longer run (once they are hit by a favorable shock).

\subsection{Aggregate Employment and Unemployment}

The employment rate of workers with ability $\alpha_{i}$ is

$$
n\left(\alpha_{i}\right)=n_{t}^{E}\left(\alpha_{i}\right) \eta_{i, t}^{E}\left(\alpha_{i}\right)+n_{t}^{U}\left(\alpha_{i}\right) \eta_{i, t}^{U}\left(\alpha_{i}\right),
$$

and the corresponding unemployment rate is

$$
u\left(\alpha_{i}\right)=1-n\left(\alpha_{i}\right),
$$

where $n^{E}$ and $n^{U}$ are the shares of elite workers and under-class workers, respectively $\left(n^{E}+n^{U}=1\right)$. For workers of intermediate ability, these shares are stationary by definition: $n_{t}^{E}=n_{t-1}^{E}$ and $n_{t}^{U}=n_{t-1}^{U}$. For workers of high ability, the share of elite workers evolves according to

$$
n_{t}^{E}=n_{t-1}^{E}+n_{t-1}^{U} \eta_{i, t}
$$

Those high-ability workers who are already elite, stay elite, while those who are underclass become elite once they find a job. This implies that in the long run all high-ability workers become elite: $n_{t}^{E}->1$ with $t->\infty$.

For workers of low ability, the share of elite workers evolves according to

$$
n_{t}^{E}=n_{t-1}^{E}\left(1-\eta_{i, t}^{E}\right)
$$

Low-ability workers retain their elite identity only as long as they do not become unemployed. Thus in the long run all these workers become underclass: $n_{t}^{E}->$ 0 with $t->\infty$.

Aggregate employment and unemployment are

$$
\begin{aligned}
& n=\int n\left(\alpha_{i}\right) g\left(\alpha_{i}\right) d \alpha_{i}, \\
& u=\int u\left(\alpha_{i}\right) g\left(\alpha_{i}\right) d \alpha_{i} .
\end{aligned}
$$




\subsection{The path-dependence of the equilibrium}

From the discussion above, it is already clear that the steady state depends on initial conditions. If an economy initially has a large proportion of elite workers in the region between $B$ and $C$, then long-run employment and output will be higher than for an economy that initially has a large proportion of underclass workers in this region. This is illustrated in Figure 4, which shows three different economies, with the same distribution of ability. ${ }^{9}$ Specifically, we use the following parameter values: $b=0.5, c=0.05, s=0.4, \beta=0.9925$. The shock distribution is assumed to be log-normal with mean 0 and standard deviation 0.4. Aggregate productivity $a$ is normalized to 1 . Ability $\alpha$ is uniformly distributed between 0.4 and $0.6 .^{10}$

In the absence of identity considerations, these economies would have the same steady-state output. Once the influence of identity on the willingness to work is taken into account, however, this is no longer the case. In Figure 4 , the three economies differ with respect to the share of elite workers at time zero. The high-ability economy is assumed initially to contain only elite workers. This is not sustainable, since the low-ability workers below B in Figure 3 switch to being underclass as soon as they are hit by a negative idiosyncratic shock, and thus aggregate employment (and output) in this economy falls over time. Note, however, that the workers between B and C stay elite. The low-ability economy initially contains $0 \%$ elite workers. Again this is not sustainable, as workers above $\mathrm{C}$ choose to be elite as soon as they are hit by a positive idiosyncratic shock, and thus aggregate employment rises over time. But since

\footnotetext{
${ }^{9}$ Note that, on account of our simplifying assumption that there are no labor turnover costs, the job finding rate is equal to the job retention rate and these, in turn, are equal to the employment rate. Consequently, the values of the employment rate of course turn out to be implausibly low. The introduction of plausibly calibrated labor turnover costs would, however, bring the employment rates back into the plausible range. Thus, the trajectories in Figure 2 are qualitatively, but not quantitatively, informative regarding employment rates.

${ }^{10}$ The main purpose of the figures is to illustrate the propositions to follow. They also demonstrate that the effects can be sizeable. However, due to the stylized nature of our model, the numbers have to be interpreted with care.
} 


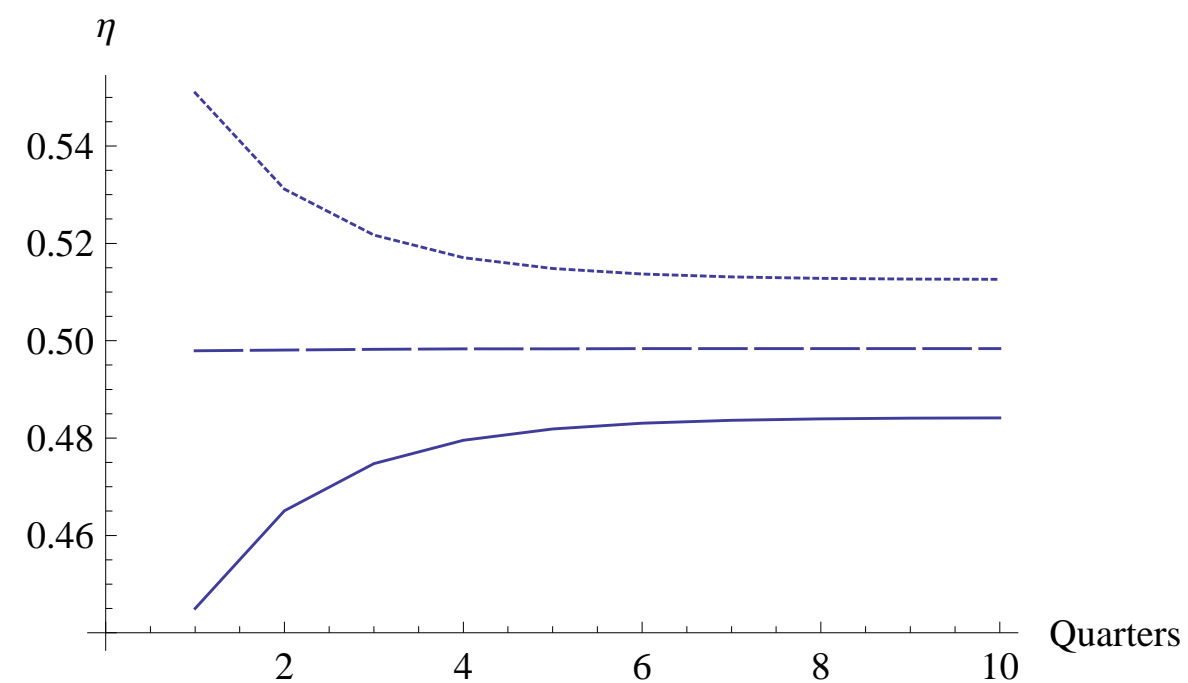

Figure 4: Trajectories of job finding rates for the high-, intermediate- and lowability economies; solid line: no elite workers; dotted line: no underclass workers; dashed line: intermediate case

workers between $B$ and $C$ stay underclass, employment in the low-ability economy is permanently lower than in the high-ability one. The intermediate-ability economy is an intermediate case in which the low-ability workers who become underclass are balanced by the high-ability workers who become elite, so that employment remains unchanged with the passage of time. The steady-state employment level in the intermediate-ability economy lies between those in the other two economies.

\section{Business cycles}

\subsection{Shocks to aggregate productivity}

In this context, we now proceed to show that business cycle fluctuations, which are typically temporary but have some persistence, can have permanent effects on aggregate employment and unemployment (and, by implication, national 
product). The reason is that these temporary fluctuations may induce workers to switch their identities and these identity choices may outlast the fluctuations.

We consider the effects of a "recession," modeled as an expected temporary decrease in aggregate productivity. Aggregate productivity is assumed to fall by 5 percent and then slowly converges back to the initial steady state, following an autoregressive process with a coefficient of autocorrelation of 0.95 .

The following proposition describes the effects of a future aggregate productivity shock, even a temporary one, on workers' value functions and identity decisions.

Proposition 3 An anticipated decrease in future aggregate productivity

- shifts down both the value function of underclass workers and the value function of elite workers, i.e., $\partial V^{E} / \partial a>0$ and $\partial V^{U} / \partial a>0$.

- shifts the value function of elite workers by more than the value function of underclass workers, i.e., $\partial V^{E} / \partial a>\partial V^{U} / \partial a$.

- shifts the identity switching thresholds in the opposite direction of aggregate productivity, i.e., $\frac{\partial \alpha^{E}}{\partial a}<0, \frac{\partial \alpha^{E}}{\partial a}<0$.

- can induce some workers to switch identity. Thus, a recession can have permanently negative effects.

(Proof in the appendix.)

Figure 5 illustrates the effects of this recession on workers' value functions. The dashed curves $V^{E}$ and $V^{U}$ represent the value functions of elite and underclass workers, respectively, during a recession. Observe that both value functions shift downwards in response to the productivity shock. Furthermore, observe that point $B$ (from Figure 3) the cutoff point between intermediate- and lowability workers rises to $B^{\prime}$, implying that more workers have an incentive to choose an underclass identity. ${ }^{11}$ Once the shock is over, the value functions return to their steady-state positions, but the workers who switched their identity

\footnotetext{
${ }^{11}$ The cutoff points $A$ and $C$ also shift to the right, but these shifts are not shown in the figure for optical simplicity.
} 
from elite to underclass maintain their new identity. This is so because they lie in the range $[B, C]$ and thus keep their identity from the past, once the shock has vanished.

Thus a temporary shock can lead to permanent identity shifts, which have a permanent effect on aggregate employment and output. In particular, the drop in aggregate productivity induces some workers to adopt permanently an underclass identity. Thus aggregate employment and output are permanently lower than in the initial steady state, since underclass workers have a lower employment probability than elite workers. In this way the model can account for the hysteresis in unemployment found in many European countries and illustrated in Figure 1 for the case of Germany.

It should be noted that the identity switch just described cannot be undone by a future positive shock, i.e., a boom period. While such a shock certainly shifts the threshold $B$ downwards, say to $B^{\prime \prime}$, this does not imply identity switches. A downwards shift in $B$ would imply that the workers in the range $\left[B^{\prime \prime}, B\right]$ now could principally have both identities. Since all workers below $B$ have an underclass identity anyway, this doesn't change anything. The identity of the workers in the range $\left[B, B^{\prime}\right]$ who switched their identity after the recession is not affected by the boom. True, the boom will bring them higher job finding rates but this is not enough to induce them to take back their elite identity.

Note, however, that a boom might nevertheless have permanent effects as well. The reason is that the threshold $C$ also shifts downwards, say to $C^{\prime \prime}$. In the steady state, workers in the range $\left[C^{\prime \prime}, C\right]$ can have both identities. During the boom they can only have an elite identity. Thus, if these workers had an underclass identity before the boom, they switch their identity during the boom and become permanently elite workers. In this way, also a temporary boom can potentially have permanent effects. Note, however, that this process is distinct from the process of identity switching during a recession, since different workers are affected (workers around $B$ during a recession, workers around $C$ during a boom).

In the end, it all depends on the initial conditions, whether booms or reces- 


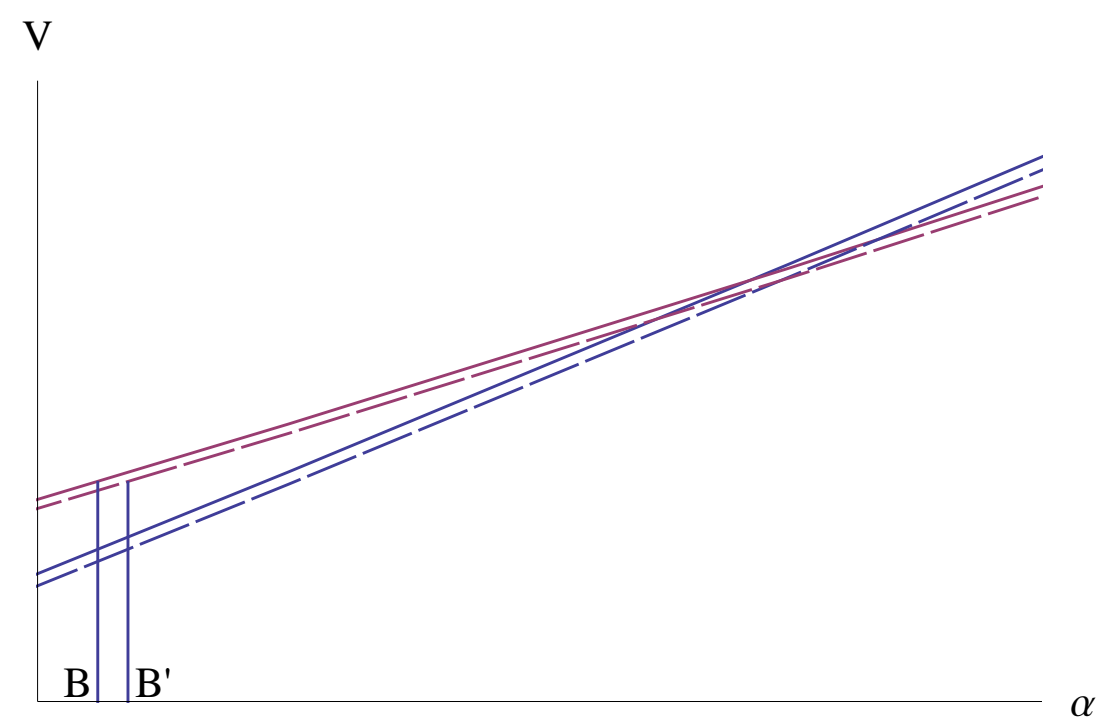

Figure 5: The effects of a recession on the value functions of elite and underclass workers; solid line: steady state; dashed line: recession

sions can have permanent effects or not. If in the old steady state all workers in $[B, C]$ had an elite identity, a recession has permanent negative effects while a boom has only temporary effects. It's the other way around, if in the old steady state all workers in $[B, C]$ had an underclass identity. Then a recession cannot have permanent effects but a boom does. In this way our model cannot only explain periods of hysteresis but also periods of downwards shifts in unemployment as the US experienced during the 1980's and 1990's.

Figure 6 shows how the job finding rate trajectory of workers in the range $\left[B, B^{\prime}\right]$ is affected by a recession (defined as above) when all workers in the ability range $\left[B, B^{\prime}\right]$ were elite before the recession. The job finding rate jumps down on impact and then slowly increases. Note however that the job finding rate does not return to its old steady state, but instead stays permanently below it.

Figure 7 shows the associated effects on utility defined as production minus 


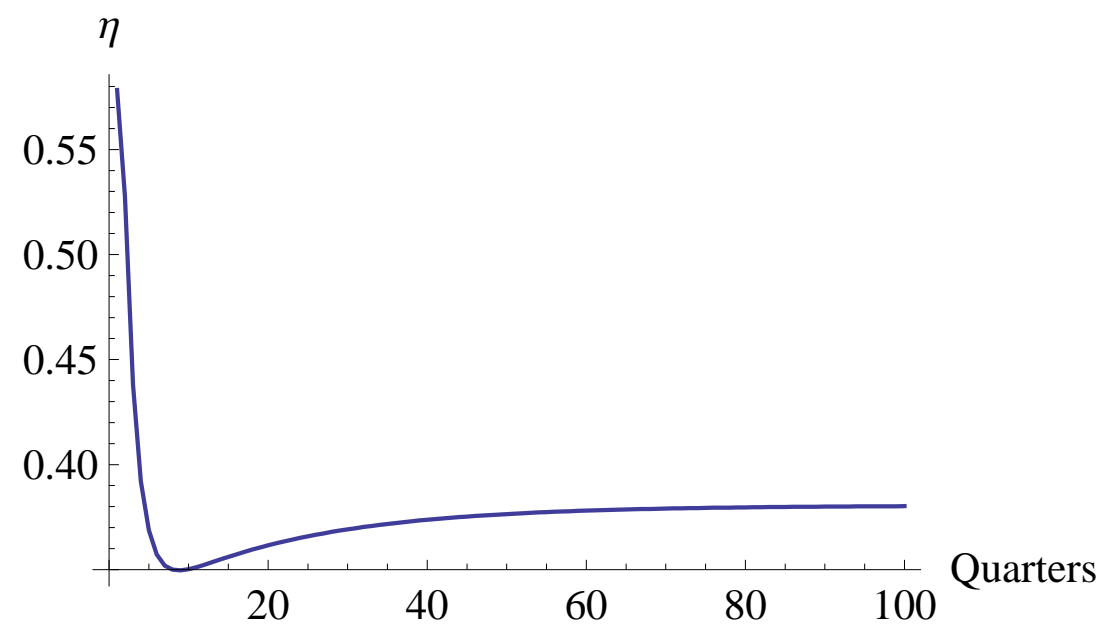

Figure 6: The effect of a recession on the job finding rate when there are many elite workers

betrayal costs minus switching costs. ${ }^{12}$ Unemployment benefits are not included since they are a pure transfer. It can be seen that utility drops during the recession and does not fully recover afterwards.

In our model, unemployment benefits are responsible for two types of economic inefficiency. The first is a conventional one, namely, that these benefits reduce workers' incentives to work (as described, for example, by Ljungqvist and Sargent (1998)). The second, an unconventional one, is related to identity choice. When a severe recession hits the economy, the existence of unemployment benefits gives elite workers an inefficiently large incentive to abandon their pro-work identity. The reason is that such workers become increasingly dependent on unemployment benefits and the costs of this dependence is borne in part by employed workers, who pay the taxes to finance the unemployment benefits. $^{13}$

By contrast, Figure 8 shows how the job finding rate is affected by the same

\footnotetext{
${ }^{12}$ Note that utility is assumed to be linear in income.

${ }^{13}$ If unemployment benefits were financed by a distortionary tax (as is common in practice) rather than by a lump sum tax (as in our model), the inefficiency would even be larger.
} 


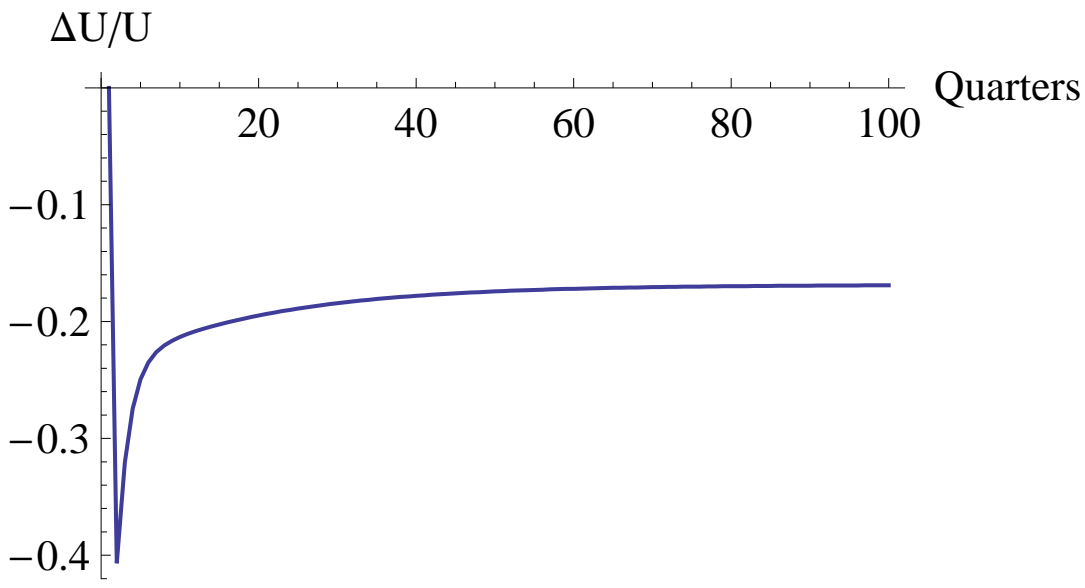

Figure 7: The effects of a recession on utility when there are many elite workers recessionary shock when all workers in the ability range $\left[B, B^{\prime}\right]$ are underclass. In this case, the recession does not have any permanent effects. The reason, of course, is that the workers in the range $\left[B, B^{\prime}\right]$ are already underclass and thus the recession does not exert any further influence on workers' identity choice. This is the kind of picture that would be generated by a standard model, without social identity.

\subsection{Determinants of Identity Switching}

In this section we discuss in more detail what factors affect the number of potential identity switchers. The following proposition summarizes how workers' identity choices are affected by workers' abilities and average productivity.

Proposition 4 Determinants of identity switching: Ability and productivity.

The number of workers who switch identity in response to a productivity shock depends positively on (i) the ratio of workers' ability to average aggregate productivity and (ii) the magnitude of the productivity shock.

(Proof in the appendix.) 


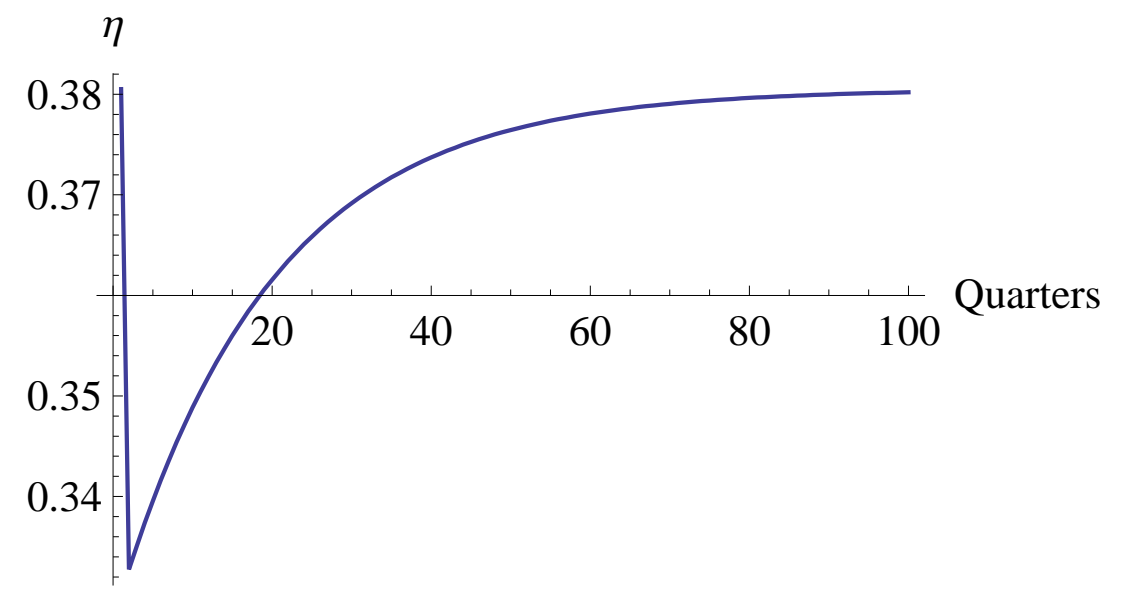

Figure 8: The effect of a recession on the job finding rate when there are few elite workers

Naturally, a larger change in productivity induces larger shifts in the value functions and the identity switching thresholds and thus the number of potential identity switchers is larger, too. The following proposition shows how identity choice depends on the identity switching costs.

Proposition 5 Determinants of identity switching: Identity switching costs.

$A$ rise in identity switching costs

- does not affect the value function of elite and underclass workers.

- decreases the number of workers who are underclass workers for sure and decreases the number of workers who are elite workers for sure.

- increases the number of workers who could potentially have both identities.

This proposition is illustrated in Figure 9. Switching costs do not have a direct impact on the value functions of elite and underclass workers since workers do not expect their identity to switch in the future. However, switching costs have an impact on the distribution of identity types. Switching becomes 
more costly and so workers are willing to accept larger differences between value functions, so that the number of workers who can potentially have both identities increases.

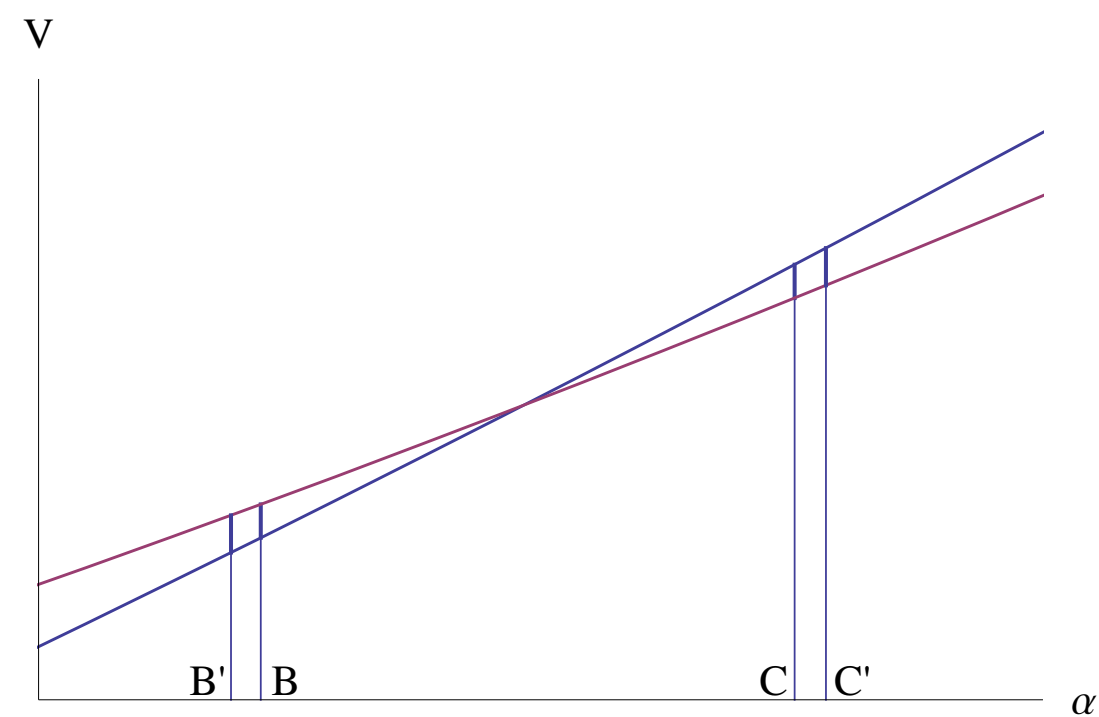

Figure 9: The effect of switching costs; $B^{\prime}$ and $C^{\prime}$ illustrate a change in $s$ from 0.4 to 0.44

Next, we examine how identity choice depends on the identity betrayal costs.

Proposition 6 Determinants of identity switching: Identity betrayal costs.

$A$ rise in identity betrayal costs

- increases unemployment among underclass workers and decreases unemployment among elite workers.

- shifts downwards both the value function of underclass workers and the value function of elite workers, i.e., $\partial V^{E} / \partial c<0$ and $\partial V^{U} / \partial c<0$.

- increases the number of workers who are underclass workers for sure and increases the number of workers who are elite workers for sure.

- decreases the number of workers who could potentially have both identities. 
(Proofs in the appendix.)

This proposition is illustrated in Figure 10. In terms of the distribution of identity types, betrayal costs have the opposite effect than switching costs. These costs make it more costly to have an identity that is inappropriate to one's employment status, and thus workers have a greater incentive to pay the cost of switching their identity. Thus the number of workers who could potentially have both identities decreases. Furthermore, there are additional, direct effects on the employment rate. Since betrayal costs obviously make identity betrayal more costly, the underclass workers are more reluctant to take up a job and their employment rate goes down. By contrast, elite workers feel less tolerant of being without a job and only take up unemployment in case of very low productivity. So their employment rate goes up.

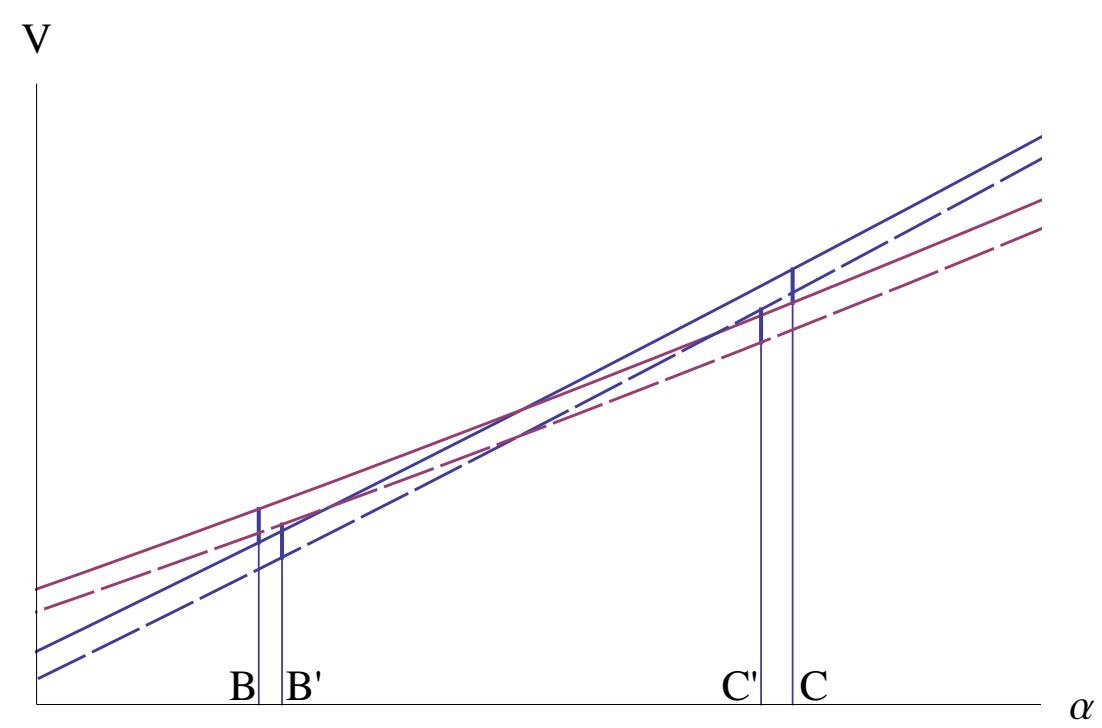

Figure 10: The effect of betrayal costs; dashed line illustrates a change in $c$ from 0.05 to 0.055

In these various ways, the determinants of identity choices influence workers' employment and unemployment rates. 


\subsection{The Unemployment Effects of Large versus Small Busi- ness Cycle Shocks}

So far we have demonstrated that temporary shocks can have permanent effects. In reality, though, not every recession brings about a permanent increase in unemployment. Our analysis, however, can also explain why some shocks have permanent effects whereas others do not. Figure 11 illustrates the effects of a large negative and a small negative productivity shock on workers' value functions.

Forecasters frequently distinguish between "standard" (relatively small and frequent) business cycle swings and "extraordinary" (relatively large and infrequent) ones. In the former case, it appears plausible that workers in the range $B$ to $B^{\prime}$ are already underclass since the relatively frequent standard shocks will have induced them to make an identity choice appropriate to their usual employment status. However, the workers between $B^{\prime}$ and $B^{\prime \prime}$ are less mobile and thus it is plausible to presume that more workers in this region still have an elite identity. These workers would not be affected by small shocks but they would be dislodged by a large shock and become underclass. It follows, that a small shock might not have permanent effects while a large shock does.

\subsection{Policy Implications}

The policy implications of the previous analysis are straightforward. If persistent, but temporary recessions can have permanent effects on workers' identity choice and thereby lead to permanent increases in unemployment, then there is an interesting case to be made for stabilization policy. By "stabilization policy," we refer not only to demand-side macroeconomic (monetary and fiscal) policies that reduce the amplitude of the business cycle, but also any other measures that prevent people from becoming unemployed in recessionary periods. The latter measures may include counter-cyclical wage subsidies, hiring subsidies for the unemployed, counter-cyclical payroll tax reductions, and so on. Since stabilization policies mitigate the effects of recessions on employment, they thereby 


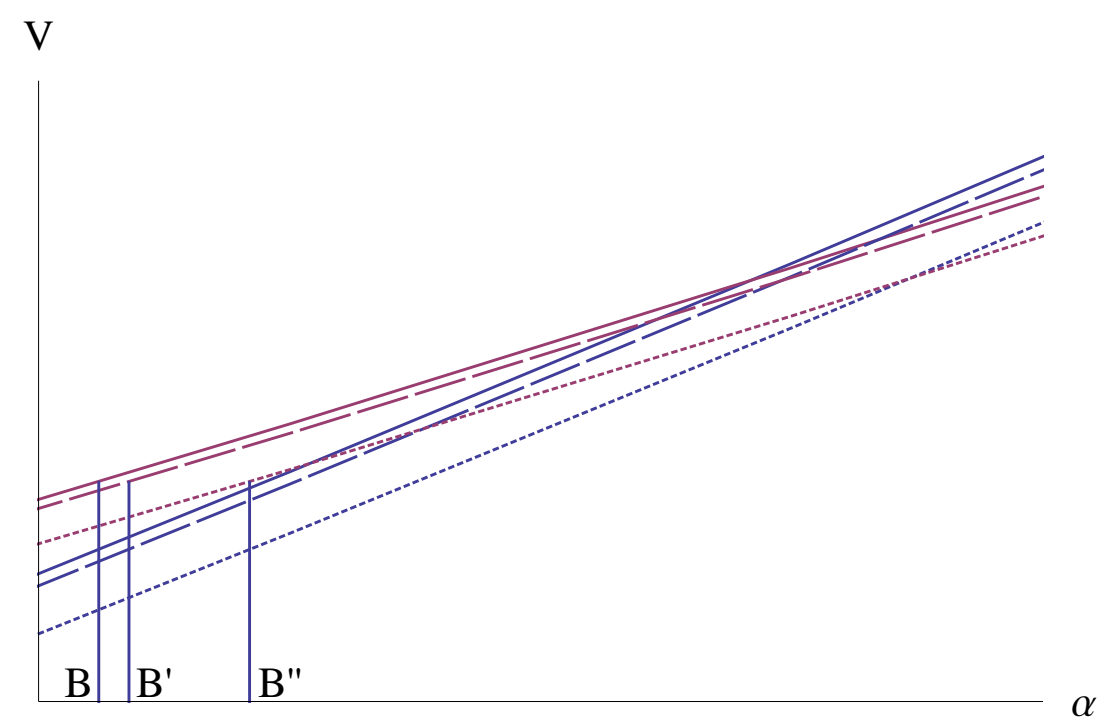

Figure 11: The size of shocks; solid line: steady state; dashed line: $1 \%$ productivity decline; dotted line: $5 \%$ productivity decline

prevent people from making identity choices in favor of an anti-work ethic and thereby prevent permanent rises in unemployment.

To fix ideas, Figure 12 shows that the identity-induced permanent effects of a recession on unemployment can be avoided through a appropriate wage subsidy. ${ }^{14}$ We consider a wage subsidy of $3.6 \%$ on impact, following an autoregressive process with the same coefficient of autocorrelation as aggregate productivity. The lower trajectory is the same as in Figure 6 in the absence of a wage subsidy, whereas the job finding rate follows the upper trajectory in the presence of the subsidy. Observe that the subsidy prevents the permanent drop in the job finding rate. This policy also prevents the occurrence of a permanent decrease in real income and utility shown in Figure 7, and thus has a permanent

\footnotetext{
${ }^{14} \mathrm{~A}$ wage subsidy that rises in response to a recession is a particularly direct way to affect the wage and thereby employment incentives, but any measure that raises employment incentives during a recession (such as counter-cyclical fiscal policy that stimulates demand and prices during recession) would be equally appropriate.
} 
positive impact on welfare.

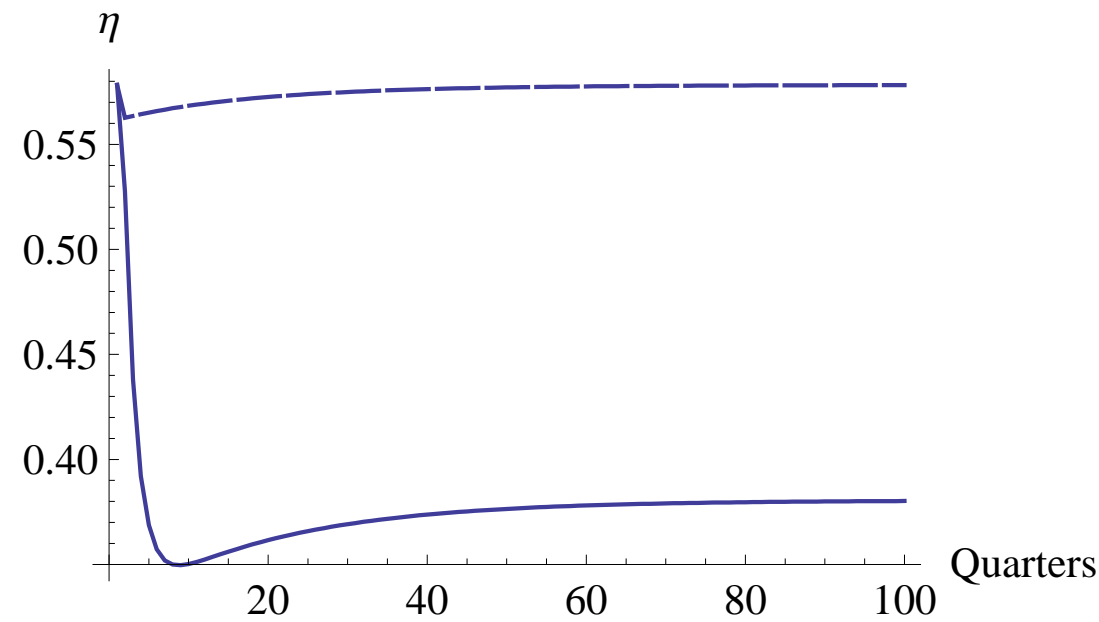

Figure 12: The effect of a stabilizing wage subsidy on the job finding rate; solid line: without subsidy; dashed line: with subsidy

The role of stabilization policy in this context is clear. If policy reacts late, so that some elite workers have already switched their identity to underclass, it will be disproportionately difficult to induce them to return to an elite identity. The reason is that a tardy, stimulative policy - say, through wage subsidies or hiring subsidies - will shift the value functions of all workers upwards (in a similar way as a boom does) and the value of being elite increases relative to the value of being underclass. But this will primarily affect workers around the threshold $\mathrm{C}$ in Figure 3, who are likely to have an elite identity anyway. By contrast, the workers around threshold $\mathrm{B}$, the ones who became underclass during the recession, are comfortable with their new identity, and will not be affected by this policy in such way as to induce them to become elite again. On this account, the government must reacts promptly to the downturn to prevent workers from becoming underclass. Once this identity switch has taken place, it is hard for policy to counteract.

Another way to illustrate our results is to analyze how the size of the govern- 
ment expenditure multiplier depends on workers' identity choices. In particular, if the government manages to avoid identity switching, the multiplier can be relatively large. We proceed to demonstrate this result with respect to the wage subsidy above. Again, we concentrate on workers in the region $\left[B, B^{\prime}\right]$.

We define the dynamic multiplier of a particular fiscal policy measure (viz., the above wage subsidy) as the discounted sum of the income effects divided by the discounted sum of the policy costs, for a given number of time periods after the policy was introduced:

$$
m(x)=\sum_{t=0}^{x} \beta^{t}\left(y_{t}-y_{t}^{\prime}\right) / \sum_{t=0}^{x} \beta^{t} g_{t}
$$

where $y_{t}$ is aggregate income in the presence of the wage subsidy, $y_{t}^{\prime}$ is aggregate income in the absence of the subsidy, $g_{t}$ is the cost of the subsidy, and $x$ is the number of periods that have elapsed since the introduction of the subsidy.

We begin by considering the multiplier in the absence of an identity switch. For this purpose, consider an economy where in the initial steady state in the ability range $\left[B, B^{\prime}\right]$ all workers are already underclass. This implies that a recession does not have permanent effects because no elite workers are induced to become underclass. However, this also means that the wage subsidy cannot play the role of preventing such a switch. The dynamic multiplier for this economy is shown by the lower curve in Figure 13. The multiplier is largest on impact and then declines slightly, converging to a value of 1.69. The drop in the multiplier is a common feature in the literature, because typically the output effects recede faster than the stimulus. ${ }^{15}$

Now consider an economy containing only elite workers in the initial state in the ability range $\left[B, B^{\prime}\right]$. Here, in the absence of a wage subsidy identity switching occurs: elite workers become underclass. As discussed above, this switch in identity can be prevented by the use of an appropriate wage subsidy. Not surprisingly, the multiplier in this context is higher, as demonstrated by the upper curve in Figure 13. This is line with recent empirical evidence showing that the fiscal multiplier is higher during economic crises (see Auerbach and

${ }^{15}$ See, e.g., Campolmi, Faia, and Winkler (2011). 
Gorodnichenko (2012) and Bouthevillain and Dufrenot (2010)). Again, we see a strong multiplier on impact and a decline in later periods, because the output effects recede faster than the stimulus, at least over an initial span of time. Beyond that, this trend is reversed because some positive output effect remains, while the costs keep on declining. This explains the increase in the multiplier in later periods.

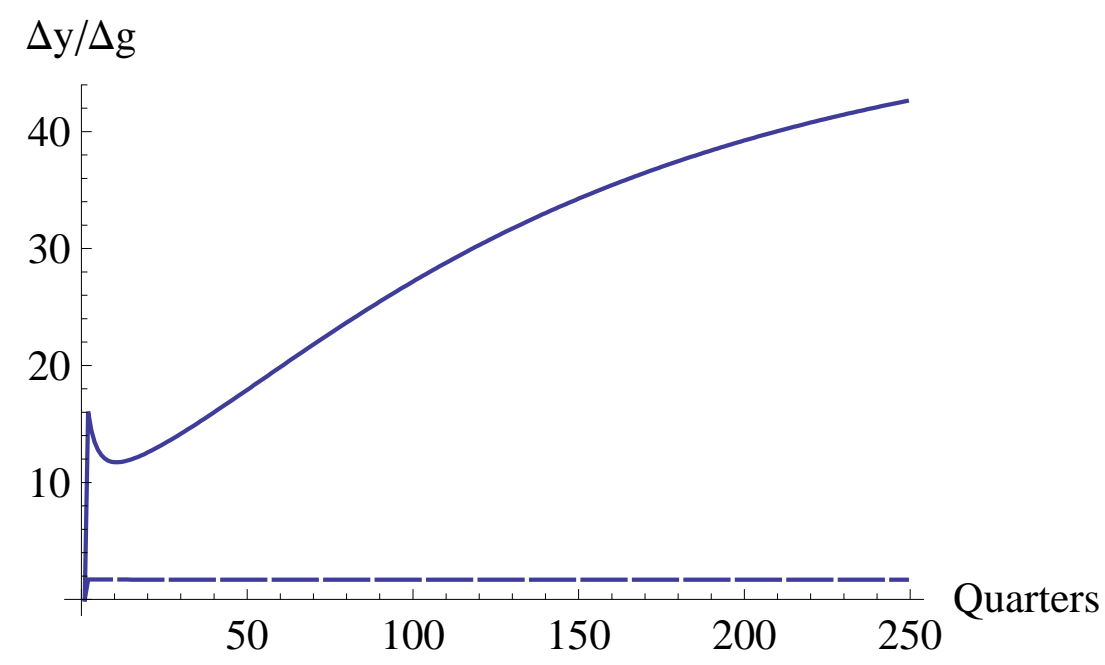

Figure 13: Accumulated multipliers; solid line: economy with many elite workers; dashed line: economy with few elite workers

Two notes of caution are at hand. (i) As noted, our stylized model is adequate for qualitative, but not quantitative, assessments. So the results should be interpreted as an indicator that a policy that prevents identity switching can have larger effects than in standard models. (ii) In the experiment above we concentrated on those workers where the effects of policy are largest, namely the workers in the region $\left[B, B^{\prime}\right]$, who potentially switch their identity during a recession. In practice, a government might not be able to concentrate its policy on those workers but instead use it over a broader range or workers. In this case the multiplier will lie somewhere in between the two lines in Figure 13. 


\section{Conclusion}

In this paper we examine the implications of social identities for labor market outcomes. In line with the empirical evidence, we assume that workers differ with respect to their attitude to work. Elite workers have a strong pro-work ethic and suffer disutility when they are unemployed. Underclass workers have an anti-work ethic and thus suffer high disutility from work. This attitude towards work affects the reservation wage and so elite workers have a higher employment rate than underclass workers.

While workers do not adjust their identity frequently, they may still react to major, prolonged changes in the economic environment. The deterioration of employment prospects during a deep, prolonged recession might induce some elite workers to lose their pro-work ethic. Since identities are sticky, they might keep their new identity even when the recession is long past. In this way, temporary shocks can have permanent effects and thus our model can explain the hysteresis in unemployment observed in many European countries.

Economic policy has a novel role in our model. Any policy that enhances wages and employment rates during a recession has the potential to avoid identity-switches. In this case, economic policy can avoid the permanent decrease in output and thus has permanent positive effects. As a consequence the multiplier can be relatively large. 


\section{References}

Akerlof, G. (1980): "A theory of social custom, of which unemployment may be one consequence," Quarterly Journal of Economics, 94(4), 749-775.

Akerlof, G., and R. Kranton (2000): "Economics and Identity," Quarterly Journal of Economics, 115(3), 715-753.

(2005): "Identity and the Economics of Organizatons," Journal of Economic Perspectives, 19(1), 9-32.

Auerbach, A., and Y. Gorodnichenko (2012): "Measuring the Output Responses to Fiscal Policy," American Economic Journal - Economic Policy, $4(2), 1-27$.

Austen-Smith, D., And R. Fryer (2005): "An economic analysis of "acting white"," Quarterly Journal of Economics, 120, 551-83.

Battu, H., M. Mwale, and Y. Zenou (2007): "Oppositional identities and the labor market," Journal of Population Economics, 20, 643-67.

Bauer, T., M. Fertig, and M. Vorell (2011): "Neighborhood effects and individual unemployment," SOEPpapers, 409.

Benabou, R., and J. Tirole (2006): "Incentives and prosocial behavior," American Economic Review, 96(5), 1652-78.

Berkovitch, E. (1990): "A stigma theory of unemployment duration," in Search Unemployment: Theory and Measurement, ed. by Y. Weiss, and G. Fishelson, pp. 20-56. MacMillan, London.

Besley, T., AND S. CoATe (1992): "Understanding welfare stigma: taxpayer resentment and statistical discrimination," Journal of Public Economics, 48, $165-183$.

Bisin, A., E. Patacchini, T. Verdier, and Y. Zenou (2011): "Ethnic identity and labour market outcomes of immigrants in Europe," Economic Policy, 26, 57-92. 
BJornstad, R. (2006): "Learned helplessness, discouraged workers, and multiple unemployment equilibria," Journal of Socio-economics, 35, 458-475.

Blanchard, O., and L. Summers (1986): "Hysteresis and the European Unemployment Problem," NBER Macroeconomics Annual, pp. 15-78.

Bouthevillain, C., And G. Dufrenot (2010): "Are the Effects of Fiscal Changes Different in Times of Crisis and Non-Crisis? The French Case," Available at SSRN: http://ssrn.com/abstract=1985183 or http://dx.doi.org/10.2139/ssrn.1985183.

Campolmi, A., E. Faia, and R. Winkler (2011): "Fiscal Calculus and the Labor Market," B.E. Journal of Macroeconomics (Contributions), 11(1), Article 38 .

Clark, A. (2003): "Unemployment as a social norm: psychological evidence from panel data," Journal of Labor Economics, 21(2), 323-351.

Clark, A., E. Diener, Y. Georgellis, and R. Lucas (2008): "Lags And Leads in Life Satisfaction: a Test of the Baseline Hypothesis," The Economic Journal, 118(529), F222-F243.

Clark, A., Y. Georgellis, and P. Sanfey (2001): "Scarring: The psychological impact of past unemployment," Economica, 68, 221-241.

Clark, A., and A. Oswald (1994): "Unhappiness and Unemployment," The Economic Journal, 104(424), 648-659.

Darity, W., and A. Goldsmith (1993): "Unemployment, social psychology, and unemployment hysteresis," Journal of Post Keynesian Economics, 16(1), $55-71$.

(1996): "Social Psychology, unemployment and macroeconomics," Journal of Economic Perspectives, 10(1), 121-140. 
Darity, W., P. Mason, and J. Stewart (2006): "The economics of identity: The origin and persistence of racial identity norms," Journal of Economic Behavior and Organization, 60(3), 283-305.

Dolan, P., T. Peasgood, and M. White (2008): "Do we really know what makes us happy A review of the economic literature on the factors associated with subjective well-being," Journal of Economic Psychology, 29(1), 94-122.

FARMER, R. (2012): "Confidecne, crashes and animal spirits," The Economic Journal, 122(559), 155-172.

Garibaldi, P., and E. Wasmer (2005): "Equilibrium Search Unemployment, Endogenous Participation, and Labor Market Flows," Journal of the European Economic Association, 3(4), 851-882.

Goldsmith, A., J. Veum, and W. Darity (1996): "The impact of labor force history on self-esteem and its component parts, anxiety, alienation and depression," Journal of Economic Psychology, 17(2), 183-220.

Hoynes, H. W. (2000): "Local Labor Markets and Welfare Spells: Do Demand Conditions Matter," Review of Economics and Statistics, 82(3), 351-368.

Kassenboehmer, S., and J. Haisken-DeNew (2009): "You're fired! The causal negative effect of entry unemployment on life satisfaction," The Economic Journal, 119, 448-462.

KLOR, E., And M. Shayo (2010): "Social identity and preferences over redistribution," Journal of Public Economics, 94(3-4), 269-278.

Koeszegi, B. (2006): "Ego utility, overconfidence, and task choice," Journal of the European Economic Association, 4, 673-707.

Lindbeck, A., S. Nyberg, and W. Joergen (1999): "Social norms and economic incentives in the welfare state," Quarterly Journal of Economics, $114(1), 1-35$. 
(2003): "Social norms and welfare state dynamics," Journal of the European Economic Association, 1(2-3), 533-542.

Lindbeck, A., and D. Snower (1986): "Wage Setting, Unemployment and Insider-Outsider Relations," American Economic Review, 76(2), 235-239.

(1987): "Union Activity, Unemployment Persistence and WageEmployment Ratchets," European Economic Review, 31, 157-167.

Ljungqvist, L., and T. Sargent (1998): "The European unemployment dilemma," Journal of Political Economy, 106(3), 514-550.

Mason, P. (2004): "Annual Income, Hourly Wages, and Identity Among Mexican-Americans and Other Latinos," Industrial Relations: A Journal of Economy and Society, 43, 817-834.

Pendakur, K., and R. Pendakur (2005): "Ethnic identity and the labour market," unpublished manuscript, Simon Fraser University.

Pissarides, C. (2000): Equilibrium Unemployment Theory. MIT Press, Cambridge.

Pries, M., and R. Rogerson (2009): "Search frictions and labor market participation," European Economic Review, 53(5), 568-587.

Stutzer, A., and R. Lalive (2004): "The role of social work norms in job searching and subjective well-being," Journal of the European Economic Association, 4, 696-719.

Sunde, U., D. Huffmann, and A. Falk (2011): "Discouragement in an equilibrium search model with type uncertainty," mimeo.

van Der KlaAuw, B., and J. C. van Ours (2003): "From welfare to work: does the neighborhood matter?," Journal of Public Economics, 87(5-6), 957985. 
VENDRIK, M. (1993): "Habits, hysteresis and catastrophes in labor supply," Journal of Economic Behavior and Organization, 20(3), 353-372.

Warr, P., And P. Jackson (1987): "Adapting to the Unemployed Role: A Longitudinal Investigation," Social Science and Medicine, 25, 1219-1244.

Winkelmann, L., and R. Winkelmann (1998): "Why are the unemployed so unhappy? Evidence from panel data," Economica, 65, 1-15.

\section{Appendix}

\subsection{Proof of Proposition 1}

Proof.

Part 1.

$$
\begin{aligned}
\frac{\partial V_{i, t+1}^{E}}{\partial \alpha} & =\sum_{k=t+1}^{\infty}\left[-\beta^{k-t-1} \frac{\partial \eta_{i, k}^{E}}{\partial \alpha}(b-c)-\beta^{k-t-1} \frac{\partial v_{i, k}^{E}}{\partial \alpha} a \alpha_{i} v_{i, k}^{E} f\left(v_{i, k}^{E}\right)\right. \\
& \left.+\beta^{k-t-1} \int_{v_{i, k}^{E}}^{\infty} a \varepsilon_{i, k} f\left(\varepsilon_{i, k}\right) d \varepsilon_{i, k}\right] \\
& =\sum_{k=t+1}^{\infty}\left[\beta^{k-t-1} \frac{\partial v_{i, k}^{E}}{\partial \alpha} f\left(v_{i, k}^{E}\right)(b-c)-\beta^{k-t-1} \frac{\partial v_{i, k}^{E}}{\partial \alpha} a \alpha_{i} \frac{b-c}{a \alpha_{i}} f\left(v_{i, k}^{E}\right)\right. \\
& \left.+\beta^{k-t-1} \int_{v_{i, k}^{E}}^{\infty} a \varepsilon_{i, k} f\left(\varepsilon_{i, k}\right) d \varepsilon_{i, k}\right] \\
& =\sum_{k=t+1}^{\infty}\left[\beta^{k-t-1} \int_{v_{i, k}^{E}}^{\infty} a \varepsilon_{i, k} f\left(\varepsilon_{i, k}\right) d \varepsilon_{i, k}\right]>0
\end{aligned}
$$




$$
\begin{aligned}
\frac{\partial V_{i, t+1}^{U}}{\partial \alpha} & =\sum_{k=t+1}^{\infty}\left[-\beta^{k-t-1} \frac{\partial \eta_{i, k}^{U}}{\partial \alpha} b-\beta^{k-t-1} \frac{\partial v_{i, k}^{U}}{\partial \alpha} f\left(v_{i, k}^{U}\right)\left(a \alpha_{i} v_{i, k}^{U}+c\right)\right. \\
& \left.+\beta^{k-t-1} \int_{v_{i, k}^{U}}^{\infty} a \varepsilon_{i, k} f\left(\varepsilon_{i, k}\right) d \varepsilon_{i, k}\right] \\
& =\sum_{k=t+1}^{\infty}\left[\beta^{k-t-1} \frac{\partial v_{i, k}^{U}}{\partial \alpha} f\left(v_{i, k}^{U}\right) b-\beta^{k-t-1} \frac{\partial v_{i, k}^{U}}{\partial \alpha} f\left(v_{i, k}^{U}\right)(b-c+c)\right. \\
& \left.+\beta^{k-t-1} \int_{v_{i, k}^{U}}^{\infty} a \varepsilon_{i, k} f\left(\varepsilon_{i, k}\right) d \varepsilon_{i, k}\right] \\
& =\sum_{k=t+1}^{\infty}\left[\beta^{k-t-1} \int_{v_{i, k}^{U}}^{\infty} a \varepsilon_{i, k} f\left(\varepsilon_{i, k}\right) d \varepsilon_{i, k}\right]>0
\end{aligned}
$$

Part 2. Since $v_{i, k}^{E}<v_{i, k}^{U}, \frac{\partial V_{i, t+1}^{E}}{\partial \alpha}>\frac{\partial V_{i, t+1}^{U}}{\partial \alpha}$.

Part 3. For $\alpha \rightarrow \infty, v \rightarrow 0$ and $\eta \rightarrow 1$. Then

$$
V_{i, t+1}^{E}=\sum_{k=t+1}^{\infty}\left[\beta^{k-t-1} \int_{0}^{\infty} a \alpha_{i} \varepsilon_{i, k} f\left(\varepsilon_{i, k}\right) d \varepsilon_{i, k}\right]
$$

and

$$
V_{i, t+1}^{U}=\sum_{k=t+1}^{\infty}\left[\beta^{k-t} \int_{0}^{\infty}\left(a \alpha_{i} \varepsilon_{i, k}-c\right) f\left(\varepsilon_{i, k}\right) d \varepsilon_{i, k}\right]
$$

Clearly, $V_{i, t+1}^{E}>V_{i, t+1}^{U}$.

For $\alpha \rightarrow 0, v \rightarrow \infty$ and $\eta \rightarrow 0$. Then

$$
V_{i, t+1}^{E}=\sum_{k=t+1}^{\infty}\left[\beta^{k-t-1}(b-c)\right]
$$

and

$$
V_{i, t+1}^{U}=\sum_{k=t+1}^{\infty}\left[\beta^{k-t-1} b\right] .
$$

Clearly, $V_{i, t+1}^{U}>V_{i, t+1}^{E}$. 


\subsection{Proof of Proposition 2}

Proof. Based on 23 and 24, for workers of very low ability it is the case that $\beta\left(V^{U}-V^{E}\right)+c=\beta \sum_{k=t+1}^{\infty}\left[\beta^{k-t} \int_{0}^{\infty} c f\left(\varepsilon_{i, k}\right) d \varepsilon_{i, k}\right]=\beta /(1-\beta) c+c=$ $c /(1-\beta)$. Thus, if switching costs are below this value, workers of the lowest ability will always be underclass.

Based on 21 and 22, for workers of very high ability it is the case that $\beta\left(V^{E}-V^{U}\right)+c=\beta \sum_{k=t+1}^{\infty}\left[\beta^{k-t} \int_{0}^{\infty} c f\left(\varepsilon_{i, k}\right) d \varepsilon_{i, k}\right]=\beta /(1-\beta) c+c=c /(1-$ $\beta$ ). Thus, if switching costs are below this value, workers of the highest ability will always be elite.

Since both functions are continuous and since the slope of $V^{E}$ is larger than the slope of $V^{U}$, both functions have to cross each other, such that $V^{E}=V^{U}$. In the vicinity of this point $V^{E}-V^{U}$ and $V^{U}=V^{E}$ are necessarily smaller than $s-c$, due to the assumption that switching costs are higher than betrayal costs. Thus, there are some workers for whom the difference in future values is not large enough to induce switching, no matter what their current identity is.

\subsection{Proof of Proposition 3}

Proof. Part 1 and part 2 are equivalent to part 1 and part 2 of proposition 1. Suppose that $a_{k}$ for any $k>t$ is changed. The effect on workers value functions is:

$$
\begin{aligned}
\frac{\partial V_{i, t+1}^{E}}{\partial a_{k}} & =-\beta^{k-t-1} \frac{\partial \eta_{i, k}^{E}}{\partial a_{k}}(b-c)-\beta^{k-t-1} \frac{\partial v_{i, k}^{E}}{\partial a_{k}} a_{k} \alpha_{i} v_{i, k}^{E} f\left(v_{i, k}^{E}\right) \\
& +\beta^{k-t-1} \int_{v_{i, k}^{E}}^{\infty} \alpha_{i} \varepsilon_{i, k} f\left(\varepsilon_{i, k}\right) d \varepsilon_{i, k} \\
& =\beta^{k-t-1} \frac{\partial v_{i, k}^{E}}{\partial a_{k}} f\left(v_{i, k}^{E}\right)(b-c)-\beta^{k-t-1} \frac{\partial v_{i, k}^{E}}{\partial a_{k}} a_{k} \alpha_{i} \frac{b-c}{a \alpha_{i}} f\left(v_{i, k}^{E}\right) \\
& +\beta^{k-t-1} \int_{v_{i, k}^{E}}^{\infty} \alpha_{i} \varepsilon_{i, k} f\left(\varepsilon_{i, k}\right) d \varepsilon_{i, k} \\
& =\beta^{k-t-1} \int_{v_{i, k}^{E}}^{\infty} \alpha_{i} \varepsilon_{i, k} f\left(\varepsilon_{i, k}\right) d \varepsilon_{i, k}>0
\end{aligned}
$$




$$
\begin{aligned}
\frac{\partial V_{i, t+1}^{U}}{\partial a_{k}} & =-\beta^{k-t-1} \frac{\partial \eta_{i, k}^{U}}{\partial a_{k}} b-\beta^{k-t-1} \frac{\partial v_{i, k}^{U}}{\partial a_{k}} f\left(v_{i, k}^{U}\right)\left(a_{k} \alpha_{i} v_{i, k}^{U}+c\right) \\
& +\beta^{k-t-1} \int_{v_{i, k}^{U}}^{\infty} \alpha_{i} \varepsilon_{i, k} f\left(\varepsilon_{i, k}\right) d \varepsilon_{i, k} \\
& =\beta^{k-t-1} \frac{\partial v_{i, k}^{U}}{\partial a_{k}} f\left(v_{i, k}^{U}\right) b-\beta^{k-t-1} \frac{\partial v_{i, k}^{U}}{\partial a_{k}} f\left(v_{i, k}^{U}\right)(b-c+c) \\
& +\beta^{k-t-1} \int_{v_{i, k}^{U}}^{\infty} \alpha_{i} \varepsilon_{i, k} f\left(\varepsilon_{i, k}\right) d \varepsilon_{i, k} \\
& =\beta^{k-t-1} \int_{v_{i, k}^{U}}^{\infty} \alpha_{i} \varepsilon_{i, k} f\left(\varepsilon_{i, k}\right) d \varepsilon_{i, k}>0
\end{aligned}
$$

Thus, any expected change in future aggregate productivity will shift both value functions.

Since $v_{i, k}^{E}<v_{i, k}^{U}, \frac{\partial V_{i, t+1}^{E}}{\partial a_{k}}>\frac{\partial V_{i, t+1}^{U}}{\partial a_{k}}$.

Part 3. The lower threshold for switching identity is defined by equation (12): $\beta\left(V^{U}-V^{E}\right)=s-c$. According to part 3 of this proposition $\frac{\partial\left(V^{U}-V^{E}\right)}{\partial a}<0$. Thus a decrease in aggregate productivity would increase the left hand side of the equation without any possibility to adjust the right hand side. Thus, we need a counteracting factor on the left hand side to restore equality. This can only be achieved by an increase in the identity switching threshold, since $\frac{\partial\left(V^{U}-V^{E}\right)}{\partial \alpha}<0$ (see Proposition 1). A similar argument holds for the upper threshold.

Part 4. Workers between the steady state switching threshold and the temporarily higher recession switching threshold will become underclass (if they are not underclass already) and keep that identity once the shock is over.

\subsection{Proof of Proposition 4}

Proof. Equations (11) and (12) implicitly define the ability of the marginal workers who are indifferent between switching their status. A shock to aggregate productivity will move these thresholds. Let us define these equations as implicit 
functions:

$$
\begin{aligned}
& V_{i, t+1}^{E}-V_{i, t+1}^{U}=\frac{s-c}{\beta}=F^{E} \\
& V_{i, t+1}^{E}-V_{i, t+1}^{U}=\frac{s+c}{\beta}=F^{U}
\end{aligned}
$$

Following the implicit function theorem, we can determine the change in the threshold for becoming an underclass worker as:

$$
d \alpha^{U}=-\frac{\frac{\partial F^{U}}{\partial a}}{\frac{\partial F^{U}}{\partial \alpha^{U}}} d a
$$

Using equations (20) and (26) this becomes:

$$
\begin{aligned}
d \alpha^{U}= & -\frac{\sum_{k=t+1}^{\infty}\left[\left[\beta^{k-t-1} \int_{v_{i, k}^{E}}^{\infty} \alpha_{i} \varepsilon_{i, k} f\left(\varepsilon_{i, k}\right) d \varepsilon_{i, k}\right]-\left[\beta^{k-t-1} \int_{v_{i, k}^{U}}^{\infty} \alpha_{i} \varepsilon_{i, k} f\left(\varepsilon_{i, k}\right) d \varepsilon_{i, k}\right]\right] d a_{k}}{\sum_{k=t+1}^{\infty}\left[\beta^{k-t-1} \int_{v_{i, k}^{E}}^{\infty} a_{k} \varepsilon_{i, k} f\left(\varepsilon_{i, k}\right) d \varepsilon_{i, k}\right]-\left[\beta^{k-t-1} \int_{v_{i, k}^{U}}^{\infty} p a_{k} \varepsilon_{i, k} f\left(\varepsilon_{i, k}\right) d \varepsilon_{i, k}\right]}= \\
& -\frac{\sum_{k=t+1}^{\infty}\left[\beta^{k-t-1} \int_{v_{i, k}^{E}}^{v_{i, k}^{U}} \alpha_{i} \varepsilon_{i, k} f\left(\varepsilon_{i, k}\right) d \varepsilon_{i, k}\right] d a_{k}}{\sum_{k=t+1}^{\infty}\left[\beta^{k-t-1} \int_{v_{i, k}^{E}}^{v_{i, k}^{U}} a_{k} \varepsilon_{i, k} f\left(\varepsilon_{i, k}\right) d \varepsilon_{i, k}\right]}
\end{aligned}
$$

It can be seen that a higher $\alpha$ and a higher $d a$ tend to increase the change in $\alpha^{U}$, while a higher $a$ has the opposite effect. This becomes even more obvious under the assumption that the change in productivity is constant. Then the equation this simplifies to:

$$
d \alpha^{U}=-\frac{d a \alpha_{i} \sum_{k=t+1}^{\infty}\left[\beta^{k-t-1} \int_{v_{i, k}^{E}}^{v_{i, k}^{U}} \varepsilon_{i, k} f\left(\varepsilon_{i, k}\right) d \varepsilon_{i, k}\right]}{a \sum_{k=t+1}^{\infty}\left[\beta^{k-t-1} \int_{v_{i, k}^{E}}^{v_{i, k}^{U}} \varepsilon_{i, k} f\left(\varepsilon_{i, k}\right) d \varepsilon_{i, k}\right]}=\frac{\alpha_{i}}{a} d a
$$

\subsection{Proof of Proposition 5}

From equations (4) and (8) it can immediately be seen that the value functions are independent of switching costs. From equations (11) it can be seen that an increase in $s$ implies an increase in the difference between $V_{i, t+1}^{E}$ and $V_{i, t+1}^{U}$. Since according to proposition $1, \partial V^{E} / \partial \alpha>\partial V^{U} / \partial \alpha$, this can only be achieved if $\alpha^{E}$ increases. A similar argument shows that $\alpha^{U}$ has to decrease. It follows that 
the number of workers of type 1 and 3 decreases, while the number of workers of type 2 (workers who could potentially have both identities) increases.

\subsection{Proof of Proposition 6}

Proof. Part 1. To see this, take the derivative of the employment rate of elite workers resp. underclass workers with respect to the betrayal cost:

$$
\begin{aligned}
\frac{\partial \eta_{i, t}^{E}}{\partial c} & =\frac{1}{\alpha_{i} a} f\left(v_{i, t}^{E}\right)>0 \\
\frac{\partial \eta_{i, t}^{U}}{\partial c} & =-\frac{1}{\alpha_{i} a} f\left(v_{i, t}^{U}\right)<0
\end{aligned}
$$

Part 2. To see this, take the derivative of $V_{i, t+1}^{E}$ and $V_{i, t+1}^{U}$ with respect to $c$ :

$$
\begin{aligned}
\frac{\partial V_{i, t+1}^{E}}{\partial c}= & \sum_{k=t+1}^{\infty}\left[-\beta^{k-t-1} \frac{\partial \eta_{i, k}^{E}}{\partial c}(b-c)-\beta^{k-t-1} \frac{\partial v_{i, k}^{E}}{\partial c} a \alpha_{i} v_{i, k}^{E} f\left(v_{i, k}^{E}\right)\right. \\
- & \left.\beta^{k-t-1}\left(1-\eta_{i, k}^{E}\right)\right] \\
= & \sum_{k=t+1}^{\infty}\left[\beta^{k-t-1} \frac{\partial v_{i, k}^{E}}{\partial c} f\left(v_{i, k}^{E}\right)(b-c)-\beta^{k-t-1} \frac{\partial v_{i, k}^{E}}{\partial c} a \alpha_{i} \frac{b-c}{a \alpha_{i}} f\left(v_{i, k}^{E}\right)\right. \\
- & \left.\beta^{k-t-1}\left(1-\eta_{i, k}^{E}\right)\right] \\
= & -\sum_{k=t+1}^{\infty} \beta^{k-t-1}\left(1-\eta_{i, k}^{E}\right)<0 \\
\frac{\partial V_{i, t+1}^{U}}{\partial c} & =\sum_{k=t+1}^{\infty}\left[-\beta^{k-t-1} \frac{\partial \eta_{i, k}^{U}}{\partial c} b-\beta^{k-t-1} \frac{\partial v_{i, k}^{U}}{\partial c} f\left(v_{i, k}^{U}\right)\left(a \alpha_{i} v_{i, k}^{U}+c\right)\right. \\
& \left.-\beta^{k-t-1} \eta_{i, k}^{U}\right] \\
= & \sum_{k=t+1}^{\infty}\left[\beta^{k-t-1} \frac{\partial v_{i, k}^{U}}{\partial c} f\left(v_{i, k}^{U}\right) b-\beta^{k-t-1} \frac{\partial v_{i, k}^{U}}{\partial c} f\left(v_{i, k}^{U}\right) b\right. \\
& \left.-\beta^{k-t-1} \eta_{i, k}^{U}\right] \\
= & -\sum_{k=t+1}^{\infty} \beta^{k-t-1} \eta_{i, k}^{U}<0
\end{aligned}
$$

Thus, an increase in betrayal costs reduces the value of both elite and underclass workers. 
Part 3 and 4. To see this, take the derivative of equations (19) and (20) with respect to $c$ :

$$
\begin{aligned}
& \frac{\partial V_{i, t+1}^{E}}{\partial \alpha \partial c}=-\sum_{k=t+1}^{\infty}\left[\beta^{k-t-1} \frac{\partial v_{i, k}^{E}}{\partial \alpha} a v_{i, k}^{E} f\left(v_{i, k}^{E}\right)\right]=\sum_{k=t+1}^{\infty}\left[\beta^{k-t-1} \frac{1}{\alpha_{i}} v_{i, k}^{E} f\left(v_{i, k}^{E}\right)\right]>0 \\
& \frac{\partial V_{i, t+1}^{U}}{\partial \alpha \partial c}=-\sum_{k=t+1}^{\infty}\left[\beta^{k-t-1} \frac{\partial v_{i, k}^{U}}{\partial \alpha} a v_{i, k}^{U} f\left(v_{i, k}^{U}\right)\right]=-\sum_{k=t+1}^{\infty}\left[\beta^{k-t-1} \frac{1}{\alpha_{i}} v_{i, k}^{U} f\left(v_{i, k}^{U}\right)\right]<0
\end{aligned}
$$

This means that an increase in betrayal costs makes the value function of elite workers steeper while it makes the value function of underclass workers flatter. Thus, the difference between $V^{E}$ and $V^{U}$ increases faster with changes in $\alpha$ if $V^{E}>V^{U}$ and it shrinks faster with $\alpha$ if $V^{E}<V^{U}$. It follows that $\alpha^{U}$ moves to the right, that $\alpha^{E}$ moves to the left and that the distance between the two thresholds becomes smaller with increases in $c$. This effect is even strengthened by the fact that $c$ also shows up directly and negatively in both equations. 